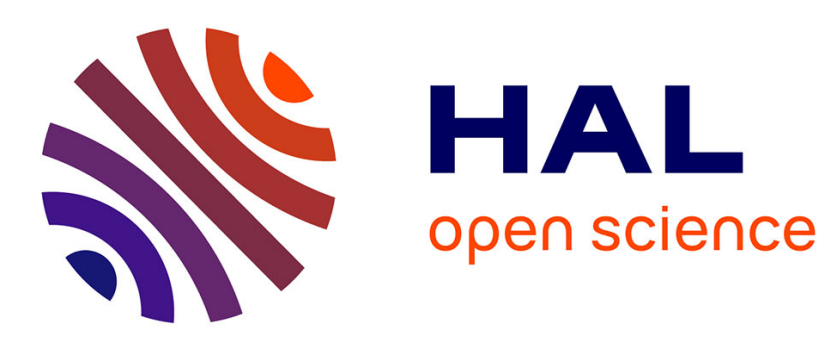

\title{
Detecting fasciculations in amyotrophic lateral sclerosis: duration of observation required
}

Kerry R Mills

\section{To cite this version:}

Kerry R Mills. Detecting fasciculations in amyotrophic lateral sclerosis: duration of observation required. Journal of Neurology, Neurosurgery and Psychiatry, 2010, 82 (5), pp.549. 10.1136/jnnp.2009.186833 . hal-00585769

\section{HAL Id: hal-00585769 \\ https://hal.science/hal-00585769}

Submitted on 14 Apr 2011

HAL is a multi-disciplinary open access archive for the deposit and dissemination of scientific research documents, whether they are published or not. The documents may come from teaching and research institutions in France or abroad, or from public or private research centers.
L'archive ouverte pluridisciplinaire HAL, est destinée au dépôt et à la diffusion de documents scientifiques de niveau recherche, publiés ou non, émanant des établissements d'enseignement et de recherche français ou étrangers, des laboratoires publics ou privés. 
Detecting fasciculations in amyotrophic lateral sclerosis: duration of observation required

Kerry R Mills PhD, FRCP (Corresponding Author)

Dept of Clinical Neurophysiology,

King's College Hospital,

London,

SE5 9RS,

UK

Tel: +44 (0) 2032998366

Fax: +44 (0) 2032994365

\section{Prof.krmills@mac.com}

The Corresponding Author has the right to grant on behalf of

all authors and does grant on behalf of all authors, an exclusive licence (or non exclusive for government employees) on a worldwide basis to the BMJ Publishing Group Ltd and its Licensees to permit this article (if accepted) to be published in the Journal of Neurology, Neurosurgery \& Psychiatry editions and any other BMJPGL products to exploit all subsidiary rights, as set out in our licence (http://jnnp .bmjjournals.com/ifora/licence.pdf).

Key words: amyotrophic lateral sclerosis, fasciculation, EMG Word count: 1209 


\section{Abstract}

A practical issue in the diagnosis of amyotrophic lateral sclerosis (ALS) is how long must the EMG be observed before a muscle can be declared free of fasciculations with some degree of certainty. To answer this question, the intervals between fasciculation potentials (FPs) were recorded from 53 muscles of 19 ALS patients. The distribution of the FP intervals found across the sample showed that to record a single fasciculation with a probability approaching unity, up to 90 s observation may be required.

\section{Background}

Clinical Neurophysiologists bear a heavy responsibility in the diagnosis of ALS, there being no reliable biological marker of the disease. Acute and chronic partial denervation seen on EMG provide diagnostic information of lower motor neuron abnormality and its distribution. Although they are found in many other conditions, fasciculations are the hallmark of the condition and it is difficult to be sure of the diagnosis in their absence. Both denervation and FPs may be seen in muscles without clinical abnormality emphasizing the importance of EMG ${ }^{1}$.

FPs may be recorded by needle or surface electrodes ${ }^{2}$ and represent the spontaneous discharge of a motor unit or a part thereof. Needle recorded FP waveforms can be highly complex probably due to distal multifocal triggering and intermittent intramuscular axonal block ${ }^{34}$ or may be simple resembling the waveform of motor units recruited by voluntary action. Their discharge rate is 
usually described as irregular or random ${ }^{5}$. A recent multi-electrode surface EMG study ${ }^{6}$ has shown that intervals may follow either a Poisson distribution as might be expected from a random rare event or a more symmetrical distribution of shorter intervals (3-15 ms), generally referred to as double FPs. The former was postulated to be related to spinal motoneuron hyperexcitability whereas the latter was thought to reflect the phase of axonal superexcitabilty ${ }^{78}$ following the first discharge. Thus study of FP discharge rate may give information allowing the neural structure generating the spontaneous potential to be identified.

The electromyographer when examining a patient with potential ALS is often faced with the question: how long should I observe this needle recording before I conclude that fasciculations are absent. The question may be less critical if denervation is clearly present or the muscle is weak, but in early cases where the presentation is in a single limb or purely bulbar, then the finding of FPs in clinically uninvolved muscles assumes much greater importance.

This short report attempts to answer this question by providing in a prospective study data on the probability of detecting FPs in relation to observation duration. Many electromyographers would be uncomfortable assigning significance to a single FP and would wait until more were seen to be confident of the finding. Hence probability values have been calculated for observing 1-5 fasciculations.

\section{Methods}


FPs were recorded with a concentric needle electrode from 53 muscles (biceps: 8, tibialis anterior: 27 , first dorsal interosseous: 17 , trapezius: 1) in 19 patients with definite ALS according to the El Escorial criteria ${ }^{910}$ modified by the Awaji consensus $^{11}$. Patients were selected after EMG had been performed on the above criteria from a sequential group of 61 referred for EMG in whom ALS was a potential diagnosis. Muscles for investigation were selected on clinical grounds with the requirement that muscles from all 4 limbs and a muscle innervated by a cranial nerve were studied in all patients. An arbitrary criterion was needed as to how long to monitor a muscle for FPs before it was included in the study. If a muscle showed no FPs on EMG after 1 minute (the current clinical practice of the author), then that muscle was excluded from analysis. It is acknowledged that this may have excluded some muscles with long inter-fasciculation intervals but had the virtue of practicality. The duration of disease in the 19 patients was between 3 and 36 months (median: 18 months, interquartile range: 10.25 months). Recording at a single needle site continued until at least $50 \mathrm{FPs}$ had been recorded. The EMG signal, bandpass filtered between $5 \mathrm{~Hz}$ and $10 \mathrm{kHz}$, was digitized at a sampling rate of $20 \mathrm{kHz}$. FPs triggered data collection using Signal 3 software (Cambridge Electronic Design, Cambridge UK). The time of occurrence of each FP from the start of the recording was logged to the nearest $m s$ and the inter-fasciculation intervals computed. For each recording, if $t_{1} \ldots t_{n}$ represent the times of occurrence of FPs, the intervals $\left(I_{1} \ldots I_{5}\right)$ were calculated from $t_{n+1}-t_{n}, t_{n+2}-t_{n}, t_{n+3}-t_{n}, t_{n+4}-t_{n}$ and $t_{n+5}-t_{n}$ for all values of $n$. The maximum values of each of these series therefore represent the longest intervals in which 
$1,2,3,4$ or 5 FPs occurred. The cumulative frequency distribution of $I_{1} \ldots I_{5}$ from the whole data set was then constructed (see Fig.1), allowing the probability of 1 $\ldots 5$ fasciculations occurring with respect to the duration of the recording to be estimated. In other words, after the needle has been inserted, what range of times may elapse before 1, 2, 3, 4 or 5 fasciculations have occurred.

\section{Results}

Of the 53 muscles, 16 had normal strength and showed no evidence of acute or chronic partial denervation on qualitative EMG, 8 were severely denervated with fibrillation and marked chronic neurogenic changes. The remainder (29) showed mild neurogenic changes and/or mild weakness. The sample therefore represented the full spectrum of the abnormality encountered in ALS. The duration of recording varied from 51.5 to $776.8 \mathrm{~s}$ giving overall fasciculation rates of from 4.03 to 116.6 FPs/min (First dorsal interosseous: 4.05 - $67.9 \mathrm{FPs} / \mathrm{min}$, Biceps $38.4-116.6 \mathrm{FPs} / \mathrm{min}$, Tibialis anterior $4.03-37.1 \mathrm{FPs} / \mathrm{min}$ and Trapezius 14.6 - 40.7 FPs/min). The longest inter-fasciculation interval in the whole data set was $92.2 \mathrm{~s}$. The cumulative frequency distributions for $I_{1} \ldots I_{5}$ are shown in Fig.1. From this can be seen, for example, that to record 5 fasciculations with a probability approaching unity, then the duration of recording should be 180 seconds, or the probability of recording $1 \mathrm{FP}$ in $30 \mathrm{~s}$ is 0.72 etc. The longest inter-fasciculation interval has a skewed distribution that could be rendered approximately normal by log transformation. The longest interval found in muscles showing clinical weakness $(n=20)$ had a mean $\pm S D$ of $23.7 \pm 23.0$ s 
compared with that from muscles showing no clinical weakness $(n=33)$ of $23.9 \pm$ 20.0s. These values are not significantly different $(t=0.66, p=0.51, D F=34)$ using log transformed data. Similarly, the mean longest interval from upper limb muscles $(n=27)$ was $21.3 \pm 20.8$ s and from lower limb muscles $(n=26)$ was $26.5 \pm$ $21.2 \mathrm{~s}$; again these are not significantly different $(t=1.67, p=0.1, D F=48)$ using log transformed data.

\section{Discussion}

Secure diagnosis of ALS relies heavily on EMG. It is required to demonstrate lower motoneuron abnormalities in a distribution that cannot be explained by nerve, plexus or root lesions. In early cases where clinical abnormalities are limited to one or two regions, then EMG assumes a greater importance being able to demonstrate EMG changes in clinically unaffected muscles. In limb onset ALS, it is also particularly important to demonstrate EMG abnormality in muscles innervated by cranial nerves ${ }^{12}$. It remains debatable whether FPs can occur in muscles showing no other EMG abnormality. Some contend that by using quantitative techniques such as macroEMG ${ }^{13}$, FPs occur exclusively in partially denervated muscle. Others ${ }^{1}$ using qualitative assessment, as has been used in the present study, find FPs in muscles with no other EMG abnormality. Nevertheless, the confident detection of FPs in ALS is of great practical importance. 
The distribution of intervals between FPs in ALS is known to be highly skewed with many short intervals and a very few long intervals ${ }^{6}$. Discharge rate may be correlated to the complexity of the FP waveform ${ }^{4}$, suggesting that the degree and recency of collateral reinnervation may be related to discharge rate. At a single needle site several different FPs may be seen, recognizable by the similarity of waveform components. It would be of interest to study the firing characteristics of individually identified FPs, but the purpose of the present study was a practical one: to determine the longest interval between FPs of any waveform since these will have the same significance for diagnosis.

The length of time an electromyographer should observe the EMG for fasciculation clearly depends on the clinical weighting to be put on the finding and on the experience of the electromyographer. Practicality is also important; watching EMG for FPs in a perfectly relaxed muscle for more than a few minutes would be difficult for both patient and physician. In early ALS cases where clinical abnormality is limited to one limb, the finding of FPs in the contralateral limb would have greater significance and would therefore warrant a longer search. Any guidance therefore must take into account the clinical situation. However, from this data it may be suggested that to be certain of recording, say, 2 fasciculations then observation should be for 2 minutes before the muscle can be confidently be declared fasciculation free (Fig.1). Similarly, if the muscle shows denervation and the electromyographer is happy to identify a single fasciculation, then the longest time needed to observe the muscle would be $90 \mathrm{~s}$. Of course in 
most instances, FPs will be found much more quickly, the above times being the longest needed before deciding that fasciculations are almost certainly absent. It should also be emphasized that FPs should not be taken in isolation as evidence for $\mathrm{ALS}^{14}$; acute and/or chronic denervation in addition in other muscles will be required. 


\section{References}

1. de Carvalho M. Pathophysiological significance of fasciculations in the early diagnosis of ALS. Amyotroph Lateral Scler Other Motor Neuron Disord 2000;1 Suppl 1:S43-6.

2. Howard RS, Murray NM. Surface EMG in the recording of fasciculations. Muscle Nerve 1992;15(11):1240-5.

3. Conradi S, Grimby L, Lundemo G. Pathophysiology of fasciculations in ALS as studied by electromyography of single motor units. Muscle Nerve 1982;5(3):202-8.

4. Janko M, Trontelj JV, Gersak K. Fasciculations in motor neuron disease: discharge rate reflects extent and recency of collateral sprouting. $J$ Neurol Neurosurg Psychiatry 1989;52(12):1375-81.

5. Buchthal F. Spontaneous electrical activity: an overview. Muscle Nerve 1982;5(9S):S52-9.

6. Kleine BU, Stegeman DF, Schelhaas HJ, Zwarts MJ. Firing pattern of fasciculations in ALS: evidence for axonal and neuronal origin. Neurology 2008;70(5):353-9.

7. Kanai K, Kuwabara S, Misawa S, Tamura N, Ogawara K, Nakata M, et al. Altered axonal excitability properties in amyotrophic lateral sclerosis: impaired potassium channel function related to disease stage. Brain 2006;129(Pt 4):953-62.

8. Nakata M, Kuwabara S, Kanai K, Misawa S, Tamura N, Sawai S, et al. Distal excitability changes in motor axons in amyotrophic lateral sclerosis. Clin Neurophysiol 2006;117(7):1444-8.

9. Brooks BR. El Escorial World Federation of Neurology criteria for the diagnosis of amyotrophic lateral sclerosis. Subcommittee on Motor Neuron Diseases/Amyotrophic Lateral Sclerosis of the World Federation of Neurology Research Group on Neuromuscular Diseases and the El Escorial "Clinical limits of amyotrophic lateral sclerosis" workshop contributors. J Neurol Sci 1994;124 Suppl:96-107. 
10. Brooks BR, Miller RG, Swash M, Munsat TL. El Escorial revisited: revised criteria for the diagnosis of amyotrophic lateral sclerosis. Amyotroph Lateral Scler Other Motor Neuron Disord 2000;1(5):293-9.

11. de Carvalho M, Dengler R, Eisen A, England JD, Kaji R, Kimura J, et al. Electrodiagnostic criteria for diagnosis of ALS. Clin Neurophysiol 2008;119(3):497-503.

12. Sonoo M, Kuwabara S, Shimizu T, Komori T, Hirashima F, Inaba A, et al. Utility of trapezius EMG for diagnosis of amyotrophic lateral sclerosis. Muscle Nerve 2009;39(1):63-70.

13. Guiloff RJ, Modarres-Sadeghi H. Voluntary activation and fiber density of fasciculations in motor neuron disease. Ann Neurol 1992;31(4):416-24.

14. Rosenfeld J. Fasciculations without fibrillations: the dilemma of early diagnosis. Amyotroph Lateral Scler Other Motor Neuron Disord 2000;1 Suppl 1:S53-6. 


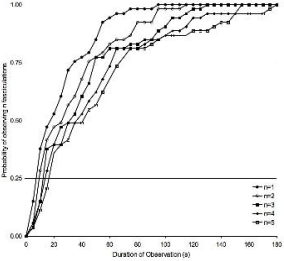

